

\section{STUDIA UNIVERSITATIS HEREDITATI}

Znanstvena revija za raziskave in teorijo kulturne dediščine

Letnik 5 , številka 2, 2017

Studia universitatis hereditati je humanistična znanstvena revija za raziskave in teorijo kulturne dediščine z mednarodnim uredniškim odborom. Objavlja znanstvene in strokovne članke s širšega področja kulturne dediščine (arheologija, arhitektura, etnologija, jezikoslovje, literarna, kulturna, glasbena, intelektualna, religijska, vojaška zgodovina, zgodovina idej itn.) in pregledne članke ter recenzije tako domačih kot tujih monografij z omenjenih področij. Revija izhaja dvakrat letno. Izdajata jo Fakulteta za bumanistične studije (Oddelek za arheologijo in dediscino) in Založba Univerze na Primorskem.

Poglavitni namen revije je prispevati k razvoju raziskav kulturne dediščine v najširšem in k topoglednemu interdisciplinarnemu pristopu $\mathrm{k}$ teoretičnim in praktičnim raziskovalnim vprašanjem. Tako revija posebno pozornost namenja razvoju slovenske znanstvene in strokovne terminologije, konceptov in paradigem na področju raziskovanja kulturne dediščine v okviru humanističnih ved.

\section{Glauni in odgovorni urednik}

dr. Gregor Pobežin (Fakulteta za humanistične študije Univerze na Primorskem, Koper)

Urednici stevilke

dr. Zrinka Mileusnić in dr. Alenka Tomaž (Fakulteta za humanistične študije Univerze na Primorskem, Koper) Tehnična ureditev revije, oblikovanje in prelom

dr. Jonatan Vinkler (Fakulteta za humanistične študije Univerze na Primorskem, Koper)

Lektor (slovenska besedila)

Davorin Dukič (Univerza na Primorskem, Koper)

\section{Uredniski odbor}

dr. Zdravka Hincak (Filozofski fakultet, Sveučilište u Zagrebu), dr. Matej Hriberšek (Filozofska fakulteta, Univerza v Ljubljani), dr. Katja Hrobat Virloget (Fakulteta za humanistične študije Univerze na Primorskem, Koper), dr. Irena Lazar (Fakulteta za humanistične študije Univerze na Primorskem, Koper), dr. Maša Sakara Sučevič (Pokrajinski muzej, Koper), dr. Alenka Tomaž (Fakulteta za humanistične študije Univerze na Primorskem, Koper), dr. Tomislav Vignjevič (Fakulteta za humanistične študije Univerze na Primorskem, Koper), dr. Jonatan Vinkler (Fakulteta za humanistične študije Univerze na Primorskem, Koper), dr. Paola Visentini (Museo Friulano di Storia Naturale, Udine)

Izdajatelj: Univerza na Primorskem - Založba Univerze na Primorskem (za Fakulteto za humanistične študije Univerze na Primorskem)

(C) 2017 Založba Univerze na Primorskem

Zanjo: prof. dr. Dragan Marušič, rektor

Titov $\operatorname{trg} 4$

SI-6000 Koper

ISSN $2350-5443$

DOI: https://doi.org/10.26493/2350-5443.5(2)

\section{(c) (i) $\circledast$}


studia universitatis hereditati 



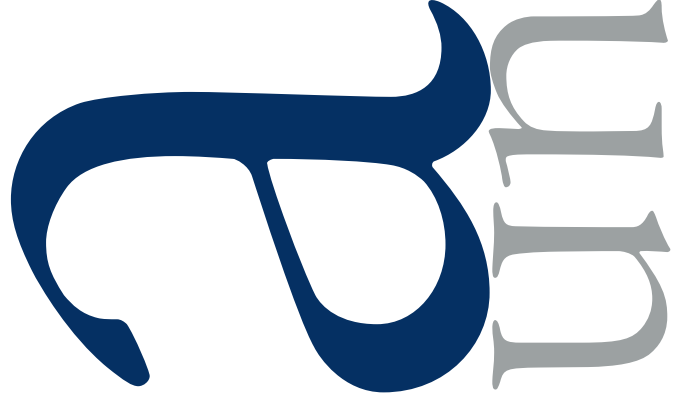

○
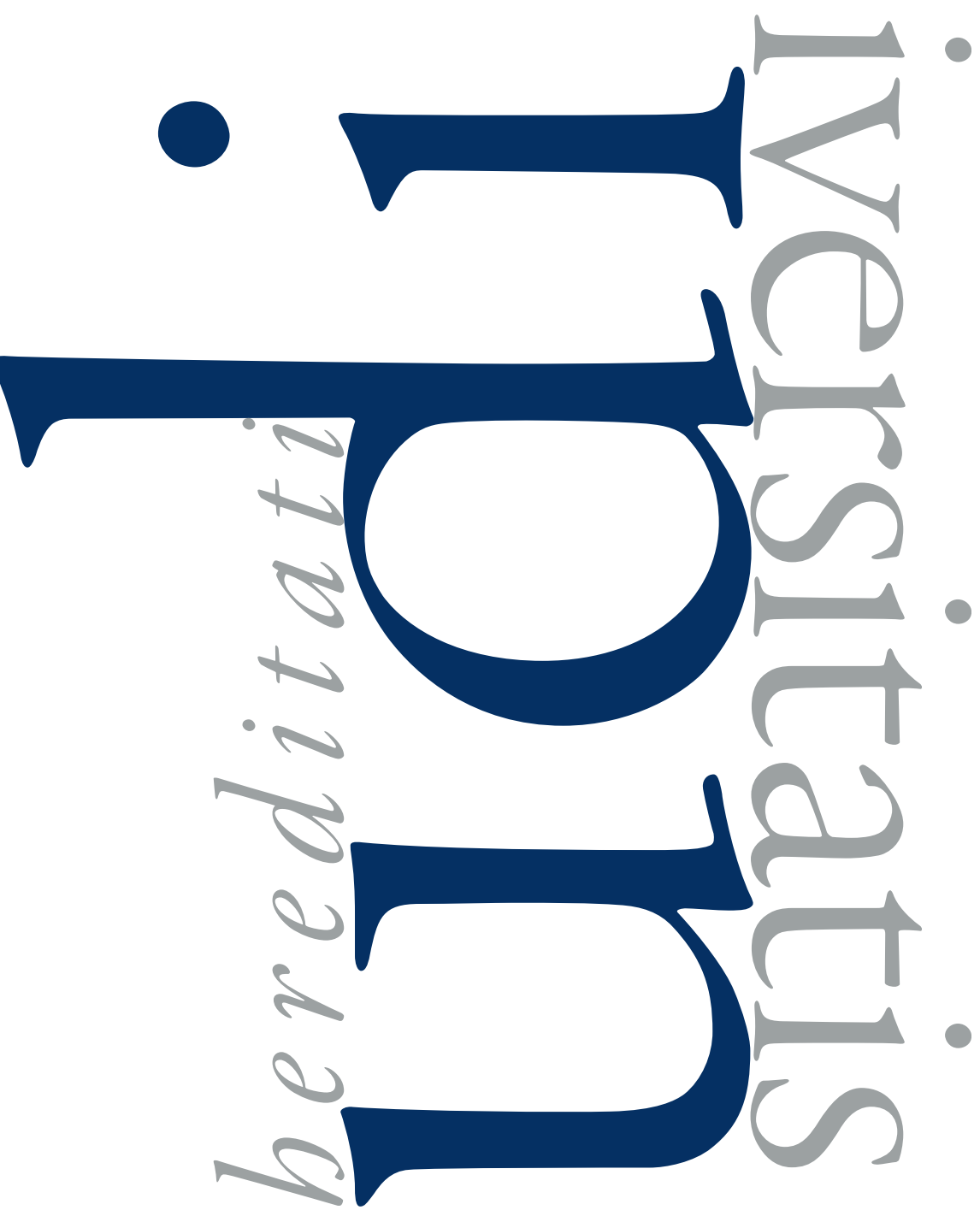

LETNIK 5

ŠTEVILKA 2

LETO 2017
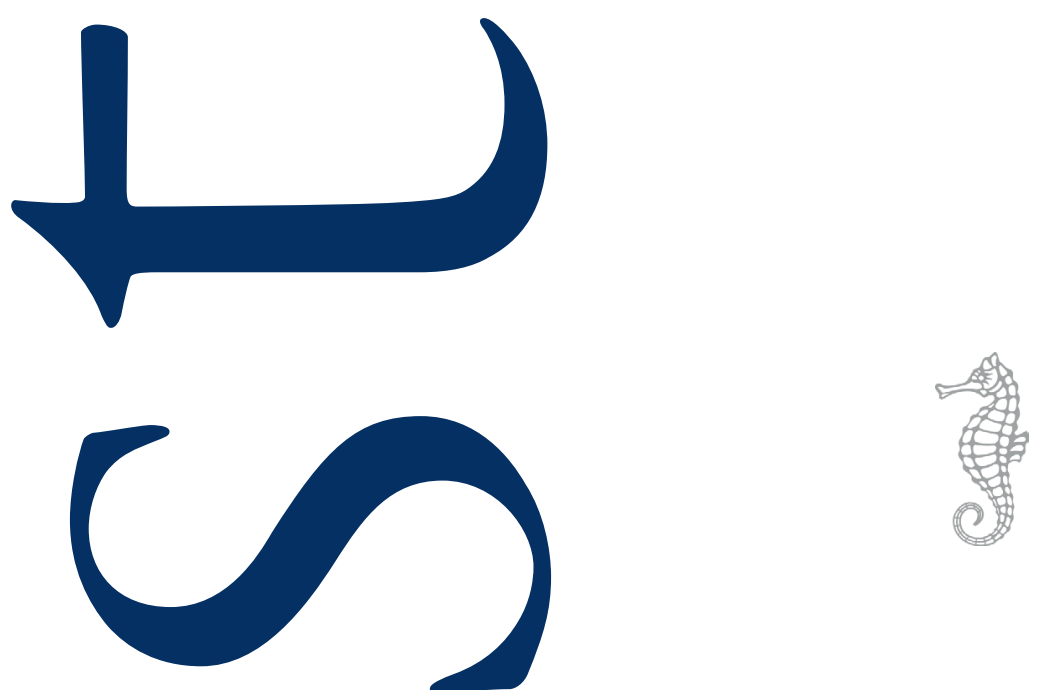
-

r

$\downarrow$

G

1

-

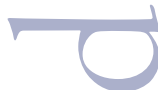

( )

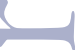

(U)

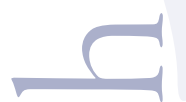




\section{Vsebina/Contents}

Julijana Visocnik, Bernarda Zupanek, Simona Jarc in Luka Gale

9 Rimski fragmenti z napisi v Mestnem muzeju Ljubljana

Jadranka Cergol

2 I I cambiamenti etnici sulla penisola Italica dalla guerra sociale alla morte dell'imperatore Augusto

Miba Mlinar

37 Rimski grob z zrcalcem z Lipičarjevega vrta na Mostu na Soči

Zdravka Hincak in Kresimir Filipec

47 Forensics and Archaeology: The Ethical Approach to Graves Excavation and Research Zorana Dimković

59 Nevidljiva dugovečnost u arheološkom kontekstu

Alenka Tomazin Maśa Sakara Sućevic

7I Arheološke raziskave na lokaciji Kaštelir nad Kortamiv letu 2014

Nenad Joncić

IOI Implementation of 3 D Scanning in Presentationand Preservation of Cultural Heritage Case Study: Dungeons of the National Museum in Pančevo 
-

r

$\downarrow$

G

1

-

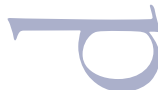

( )

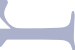

(U)

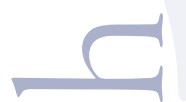




\title{
I cambiamenti etnici sulla penisola Italica dalla guerra sociale alla morte dell' imperatore Augusto
}

\author{
Jadranka Cergol, Università del Litorale, Facoltà di studi umanistici
}

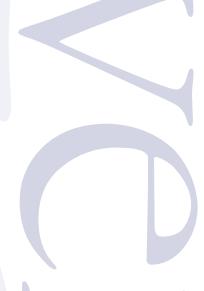

Cilj prispevka je predstaviti na podlagi starogrških in latinskih zgodovinskih virov spremembe v etnični sestavi italskega polotoka v prvem stoletju pr. Kr., natančneje od zavezniške vojne (9I - 88 pr. Kr.) do Avgustove smrti (I4 po Kr.). Zgodovinski viri iz republikanske dobe predstavljajo namreč italska ljudstva kot ostre nasprotnike nadvladi rimskega mesta, nasprotno pa, viri iz cesarske dobe opisujejo ista ljudstva kot bratska ljudstva Rimljanom. Potrebno je tudi poudariti ugotovitev, da po Avgustovi smrti imena Etruščanov, Sabinov, Umbrov, Samnitov in drugih niso več uporabljena v rimskem zgodovinopisju in polagoma izginjajo iz političnih zemljevidov italskega polotoka: ostanejo samo Rimljani in Italiki, ostane samo Italia kot enotna dežela. Kljub izkoreninjenju italskih ljudstev pa so nekatera od teh, npr. Etruščani, znatno obogatili rimsko družbo s svojimi kulturnimi značilnostmi.

Ključne besede: etnična identiteta, Italiki, rimska zgodovina, Avgust, Etruščani, Samniti

Lo scopo principale del contributo è illustrare sulla base di fonti greche e latine i cambiamenti della composizione etnica sulla penisola italica nel primo secolo a. C., più precisamente dalla guerra sociale (9I-88 a. C.) alla morte di Augusto ( 14 d. C.). Le fonti storiche di età repubblicana, infatti, descrivono le popolazioni italiche come acerrime nemiche che avevano combattuto contro Roma, mentre quelle di età imperiale parlano di popolazioni che erano addirittura consanguinee ai Romani. Bisogna anche notare che dopo la morte di Augusto i nome degli Etruschi, Sabini, Umbri, Sanniti e altri non vengono più utilizzati dalla storiografia romana perché queste popolazioni scompaiono dalla cartina geografica e politica della penisola italica: rimangono soltanto i Romani e gli Italici, rimane soltanto l'Italia come un unica regione. Nonostante l'estirpazione delle popolazioni italiche però alcuni gruppi etnici, come gli Etruschi, arricchirono essenzialmente la storia e la società romana con le proprie componenti culturali.

Parole chiave: identità etnica, Italici, storia romana, Augusto, Etruschi, Sanniti

$\mathrm{N}$

egli ultimi decenni si può notare un nuovo interesse nella ricerca delle questioni etniche anche nel campo degli studi sull'antichità. La teoria strumentale, che si basava sulla convinzione che il sentimento di appartenenza etnica fosse soltanto un pretesto per conseguire risultati politici o economici, ${ }^{\mathrm{I}}$ è risul-

Donald L. Noel, "A Theory of the Origin of Ethnic Stratification". Socialproblems 16, no. 2 (1968): 28-34. tata essere insufficiente. Negli anni '70 e '8o del secolo scorso si è quindi avuta una rinascita delle ricerche antropologiche sulla questione dell'appartenenza etnica. La questione dei gruppi etnici nell'antichità pone il ricercatore moderno dinanzi a un gran dilemma, in quanto già i termini stessi come nazione o popolo, utilizzati per l'appartenenza etnica, sono concetti implicitamente radicati che si sono affermati appena dal XVII 
secolo in poi e quindi si adattano con difficoltà alla concezione di ethnos nell'antichità. Nonostante tutte queste perplessità e questi ostacoli, secondo i ricercatori contemporanei si può parlare di appartenenza etnica anche nel contesto dell'antichità classica, in quanto sia in Grecia, sia nell'impero Romano e altrove nel Mediterraneo, le persone si incontravano, si univano, combattevano in guerre anche in base al principio di etnia. ${ }^{2}$ Un'analisi sociale e storica approfondita sull'origine delle popolazioni può quindi contribuire a una comprensione migliore dei sentimenti e dei legami che le identità culturali collettive costruiscono nel corso di molte generazioni. ${ }^{3}$

Per la definizione del gruppo etnico saranno addottati come criteri principali quelli definiti da Anthony Smith che ne elenca sei: nome comune, mito comune di origine, memoria storica comune, cultura comune, appartenenza ad un dato territorio e il senso di solidarietà comune. ${ }^{4}$

\section{Definizione del problema}

Nel periodo del principato di Augusto ci furono importanti cambiamenti nel campo delle questioni etniche: la politica interna del princeps, infatti, tendeva all'unificazione di tutte le genti italiche in un'unica unità politica. Il contributo si propone di esaminare prima l'inquadramento storico-politico dei fatti accaduti, ma soprattutto analizzare come l'unificazione etnica della penisola venisse percepita sia dai Romani che dalle varie popolazioni italiche: come esempio saranno esaminati i casi degli Etruschi e dei Sanniti.

La penisola italica è stata nel corso dell'espansione dello stato romano abitata da varie popolazioni diversamente sviluppate sul piano eco-

2 Erich Gruen, Culture and National Identity in Republican Roma (New York: Ithaca, 1984); Kathrin Toll, "Making Roman-ness and the Aeneid", Classical Antiquity" 16 (1997): 34-56; Lucia Aigner-Foresti, "Quod discinctus eras, animo quoque, carpitur unum « (Maec., El. 1.21)", Contributi dell'stituto di Storia Antica 17 (1991): 201-214; Jonatan M. Hall, Ethnic Identity in Greek Antiquity (Cambridge: Cambridge Core, 1997); Yasmin Syed, Vergil's Aeneid and the Roman Self (Ann Arbor: The University of Michigan Press, 2005); Gary D. Farney, Ethnic identity and aristocratic Competition in Republican Rome (Cambridge: Cambridge University Press, 2007).

3 Anthony D. Smith, The Ethnic Origins of Nations (Oxford: Blackwell Publishers, 1986).

4 Smith, The Ethnic Origins, 66-83. nomico, culturale, politico e sociale. Per l'epoca arcaica è molto difficile tracciare un quadro etnico preciso, perché le fonti sono incerte e tra di loro discordanti. Rimane comunque un fatto indiscusso che la penisola italica fu ancora nel terzo secolo a. C., quando i Romani avevano in un modo o nell'altro ottenuto il controllo politico su tutta la penisola, un territorio etnico misto. Se da una parte Roma manteneva il controllo sugli Etruschi soprattutto tramite accordi politici e forti collegamenti con l'aristocrazia etrusca, con i Sanniti dovette combattere numerose battaglie ${ }^{5}$. L'espansione del popolo romano però non fu sempre efficace; i Romani dovettero spesso scontrarsi con le popolazioni italiche autoctone che riuscivano a volte a fermare la loro affermazione con rivolte organizzate. Gli scontri tra $i$ Romani e le singole popolazioni risalgono già a epoche più remote, ma la prima grande battaglia si ebbe nel 295 a. C. (battaglia del Sentino), quando una confederazione anti-romana, formata da più tribù italiche, si ribellò ai Romani. I fautori della ribellione furono i Sanniti, ai quali però si aggiunsero gli Etruschi, parte degli Umbri e alcuni Galli; la confederazione è stata formata dalle popolazioni che vivevano a nord e a sud di Roma per attaccare la città da entrambe le direzioni. A causa delle dinamiche la battaglia venne da alcuni ricercatori chiamata anche "la battaglia delle nazioni” (ad es. G. Bandelli ${ }^{6}$ ), dato che alcune popolazioni italiche di diversa origine etnica si sono alleate contro un nemico comune - il popolo romano. Nella battaglia gli italici furono sconfitti, Roma invece continuò nella sua politica espansionistica sulla penisola italica.

Nonostante l'efficiente forza politica romana, alcune popolazioni italiche mantenevano in gran parte la propria autonomia con differenze evidenti da regione a regione; le principali diversità tra queste popolazioni era una più o meno sviluppata autocoscienza e il senso di apparte-

Guido Clemente, Guida alla storia romana (Milano: Mondadori, 2001); Kathryn Lomas: Roman Italy: 338 BC - AD 200 (London: Ruotledge, 1996).

Gino Bandelli: "La politica romana nell'Adriatico orientale in età repubblicana", in Seminario storico-archeologico su "L'arco adriatico in età romana e altomedievale" (Trieste, 1986): 168-214. 
nenza al proprio gruppo etnico e la preservazione delle proprie tradizioni, e questo soprattutto dopo l'assoggettamento da parte dello stato romano.

Ciò che possiamo sicuramente affermare sul processo di romanizzazione è che di cruciale importanza fu proprio il periodo tra la guerra sociale e la morte di Augusto - periodo, durante il quale il latino diventò la lingua predominante e durante il quale molte tradizioni culturali vennero introdotte nell'idea di romanitas, che si rispecchia nel sempre più alto grado di assimilazione tra gli aristocratici romani e italici. Bisogna rilevare che la romanizzazione non fu un processo unilaterale (...), si può citare territori, sui quali gli ltalici segnarono la cultura romana. ${ }^{7}$

Possiamo dedurre che il processo della lenta romanizzazione ottenne il suo scopo appena all'inizio del principato di Augusto che nelle proprie Res gestae scrisse: "Iuravit in mea verba tota Italia sponte sua ${ }^{8}$ - il primo imperatore romano aveva quindi l'idea che l'Italia fosse diventata un'unità politica e culturale omogenea o almeno questo era quello che voleva fare credere.

La conquista della penisola italica rappresentava un progetto a lungo termine, i Romani suggellavano con le popolazioni sottomesse vari tipi di rapporti, perché l'annessione dei territori conquistati all'ager romanus non era possibile. La soluzione più spesso trovata era di siglare dei patti con l'aristocrazia locale e così lasciare l'autonomia al territorio, assicurandosi però il controllo politico. Solo raramente i Romani erano costretti ad assoggettarsi direttamente le popolazioni sconfitte e mantenere il controllo diretto sul territorio. Questo succedeva principalmente con le popolazioni che si opponevano più a lungo e più aspramente. La forma più diffusa di assegnazione dei diritti politici era la fondazione di colonie, cioè città, nelle quali gli abitanti erano principalmente cives sine suffragio, cioè cittadini romani senza diritto di voto, a differenza dei $c i$ -

\footnotetext{
Lomas, Roman Italy.

Aug. Res gestae, 25 .
}

ves optimo iure, cioè dei cittadini romani con il diritto di voto. Così nascevano colonie che erano abitate sì da cittadini romani che però non avevano il diritto fondamentale di votare e quindi non potevano partecipare alle decisioni politiche dello stato romano.

La seconda forma di collaborazione con lo stato romano era la latinitas; chi otteneva il titolo di Latinus era un'abitante della penisola italica con alcuni diritti e doveri all'interno dello stato romano, come per es. la possibilità di commerciare e di contrarre matrimoni con cittadini romani e addirittura una forma limitata di collaborazione nella vita politica romana. A questo punto è necessario rilevare che entrambe le condizioni politiche (cioè Romanus, sia sine suffragio che optimo iure, come anche il Latinus) non dipendevano dall'appartenenza etnica degli abitanti o dalla loro origine genealogica: chiunque poteva diventare cittadino romano grazie ai meriti che otteneva o per altre vie? ${ }^{9}$ Massimo Cacciari sintetizza il senso della cittadinanza romana:

$$
\begin{aligned}
& \text { Civitas romana in quanto civitas augescens, città } \\
& \text { che esiste in virtù della sua capacità di incor- } \\
& \text { porare in sé nuove genti e nuovi territori, che } \\
& \text { neppure potrebbe sopravvivere se non ten- } \\
& \text { desse all’ imperium sine fine". Perciò quel- } \\
& \text { la di civitas aúescens ravoresenta l'idea chiave } \\
& \text { per comprendere lo stesso mito dell'impero } \\
& \text { universale. Poiché non è pianta che sorga da } \\
& \text { una terra e da un sangue, poiché, in questo } \\
& \text { senso, non ha radice, la civitas romana è desti- } \\
& \text { nata ab origine a crescere sempre. Nulla può } \\
& \text { "immobilizzarla”. Poiché la sua origine (po- } \\
& \text { tissima pars!) esclude ogni idea di "purez- } \\
& \text { za”, essa potrà comprendere in sé, assimi- } \\
& \text { lare-trasformare in sé, ogni popolo e ogni } \\
& \text { terra, essere Ecumene, essere Orbis, diventare } \\
& \text { per tutti Asylum. }
\end{aligned}
$$

Una terza forma di alleanza con lo stato romano erano i foederati, detti anche socii, cioè al-

\footnotetext{
9 Lomas, Roman Italy.

Io Massimo Cacciari, "Digressioni su impero e tre Rome", Micromega $5(2001): 43-63$.
} 
leati, con i quali i Romani suggellavano diversi trattati con vari diritti e doveri in base alla situazione dei singoli gruppi etnici. Valeva comunque la regola principale del "maiestatem populi Romani comiter conservare" (conservare unanime la forza del popolo romano), secondo la quale i soci collaboravano nelle guerre, ogniqualvolta si trattava della salvezza del popolo romano ${ }^{\mathrm{II}}$. Le varie popolazioni italiche erano nella maggior parte quindi foederati, ai quali erano stati concessi dei privilegi in cambio del loro servizio militare a favore dei Romani, come per esempio il conubium e il commercium. I Romani creavano con tutti i foederati soltanto alleanze bilaterali che non permettevano loro una politica esterna autonoma evitando così che si formassero alleanze anti-romane. Il compito principale degli alleati era di aiutare lo stato romano a difendersi in caso di attacchi, mentre le popolazioni erano del tutto autonome nelle questioni interne. Questo sistema offriva molti vantaggi allo stato romano, aveva infatti a disposizione un forte esercito e non investiva risorse finanziarie nell'amministrazione di tutto il territorio italico. Inoltre i Romani mantenevano il controllo politico su tutto il territorio, mentre alle popolazioni alleate non era permesso allearsi tra di loro. Il gruppo più ristretto e più elitario era certamente quello dei cittadini con tutti i diritti romani, ai quali seguivano un numero maggiore di cittadini sine suffragio.

Le possibilità di ottenere queste diverse forme di cittadinanza romana erano varie. Il modo più diffuso e comune era quello che Roma concedesse la cittadinanza ad un determinato gruppo di persone, etnico e politico. Le fonti antiche testimoniano che questo tipo di conferimento della cittadinanza era considerato da parte della comunità come una punizione, perché perdeva la propria autonomia e diventava quindi politicamente sottomessa a Roma ${ }^{\mathrm{I} 2}$. I Romani fondavano colonie con cittadini sine suffragio in quelle posizioni strategiche che permettevano loro di

\footnotetext{
I I Adrian Nicholas Sherwin.White, The Roman Citizenship (Oxford: Oxford University Press, 1939).

I2 Sherwin.White, The Roman Citizenship.
}

controllare meglio il territorio ${ }^{\mathrm{I}}$. D'altra parte le colonie latine erano invece più grandi e organizzate nei territori con un livello basso di urbanizzazione con lo scopo di sollecitare l'emigrazione della popolazione romana in queste terre. Già nell'anno 296 a. C. alcune popolazioni strinsero un patto di alleanza che insidiò gravemente Roma. Da allora in poi i Romani fondavano solo colonie con cittadini sine suffragio nell'Italia centrale formando così una fascia di territorio che correva attraverso tutta la penisola, dal mare Adriatico al mare Tirreno, dividendo così le popolazioni settentrionali da quelle meridionali e fermando ogni tentativo di alleanze tra le popolazioni italiche che appunto non avvenne fino all'anno 90 a. C.

\section{Il senso di appartenenza etnica delle popolazioni italiche prima e dopo} la guerra sociale

I trattati tra lo stato romano e le altre popolazioni della penisola italica permettevano da una parte a Roma di avere una forza militare cospicua, dall'altra invece portarono ad uno squilibrio politico tra gli alleati e lo stato romano. Le popolazioni italiche si rendevano conto della propria forza militare e chiedevano spesso di inserirsi attivamente nel processo politico dello stato romano richiedendone la cittadinanza.

Il problema dell'assegnazione della cittadinanza romana (civitas romana) ai socii era stato più volte oggetto di dibattito nel senato romano, ma non si arrivò mai ad un accordo comune. $\mathrm{Al}$ tempo dei fratelli Gracchi nell'anno I25 a. C. la questione fu di nuovo aperta dal console Marco Fulvio Flacco, ma il senato respinse la sua proposta. Alcuni anni più tardi il tribuno della plebe Livio Druso con l'aiuto degli alleati italici fece eleggere molte leggi a favore del popolo, agli alleati aveva invece promesso la legge sulla cittadinanza romana. Dalle Perioche di Tito Livio si evince che Livio Druso era stato a causa di questo odiato e considerato come l'iniziatore del-

13 Lomas, Roman Italy. 
la guerra sociale. ${ }^{\mathrm{I}}$ Quando il senato rifiutò per l'ennesima volta di conferire agli alleati la cittadinanza romana, il tribuno Livio Druso fu assassinato e nel 9r a. C. gli alleati si ribellarono provocando la guerra sociale (9I - 89 a. C.). Otto tribù italiche si allearono in una confederazione politica anti-romana, chiamata Italia con la capitale nella città di Corfino (al centro geografico della penisola) ribattezzata per l'occasione anch'essa in Italia, ovvero nella lingua degli Oschi in Viteliu. La confederazione coniò anche il proprio denaro, sul quale era raffigurato il toro italico che aggredisce e sbrana la lupa romana. I socii avevano quindi completamente abbandonato il progetto iniziale di diventare parte dello stato romano e si prefissero uno scopo contrario, cioè formare una nuova entità politica, lo stato italico. Gli ideatori del nuovo stato furono i Sanniti e i Marsi che erano nel contempo i più acerrimi nemici dell'espansione romana sulla penisola italica, gli Etruschi e gli Umbri invece decisero di non prendere parte alla confederazione italica ${ }^{\text {15 }}$.

All' inizio della sedizione i Romani subirono molte sconfitte, perché non avevano a disposizione quella forza bellica che prima l'offrivano gli alleati; potevano solo contare sull'aiuto dei Galli della Cisalpina e dei soldati che arrivavano da lontano. Dopo i successi ottenuti dagli Italici, si aggregarono a loro anche gli Etruschi e gli Umbri. L'anno successivo i Romani decisero di risolvere la questione con la Lex Iulia de civita$t e$, secondo la quale fu concessa la cittadinanza a quegli alleati che restarono fedeli a Roma, e poco dopo con la Lex Plautia Papiria dedicata a quelli che in sessanta giorni avrebbero abbandonato le armi e si sarebbero aggregati ai Romani, lo status di latinus fu invece attribuito agli abitanti della Gallia Cisalpina (Lex Pompeia de Transpadanis). Già queste leggi cambiarono l'assetto politico della penisola, nonostante la forza politica dei socii era rimasta limitata, dato che erano stati inseriti soltanto in otto tribù territoriali e non

\footnotetext{
I4 »Propter quae Livius Drusus invisus etiam senatui factus velut socialis belli auctor, incertum a quo domi occisus est.« (Livy, Per. $71,4)$.

I5 Rajko Bratož, Rimska zgodovina (Ljubljana: Študentska založba, 2007).
}

in tutte le trentacinque, quante ce n'erano nello stato romano. I conflitti si protrassero ancora per un anno nella zona dei Sanniti, ai quali venne in aiuto anche il re del Ponto Mitridate. Nell'anno 88 a. C. comunque tutte le ostilità terminarono $\mathrm{e}$ tutta la penisola divenne ager romanus.

La conclusione della guerra sociale con l'approvazione delle leggi però rappresenta "un punto di svolta, quando Roma decise di diventare da una città stato con comunità alleate legate con i trattati (in posizione legalmente inferiore) ad uno stato anche territorialmente allargato, nel quale tutti i liberi cittadini hanno una cittadinanza unitaria (...). Quelle comunità che prima erano formate dai Latini e dai socii, si sono estinte con l'introduzione di una cittadinanza romana uguale per tutti. L'assegnazione della cittadinanza romana agli abitanti di tutta l'Italia è diventata la base per la formazione di una coscienza italica e del senso di appartenenza alla comunità italica. Questi cambiamenti etnici si sono poi conclusi nel periodo del principato augusteo." $^{\text {'6 }}$

Molti ricercatori sono convinti nel pensare che con la guerra sociale il processo di romanizzazione delle popolazioni italiche abbia avuto un risvolto decisivo: il rapporto del popolo romano verso gli abitanti della penisola italica cambiò radicalmente: mentre prima della guerra il senato romano aveva perennemente rifiutato la cittadinanza agli Italici e non si preoccupava di aggregare tutte le popolazioni italiche in una tradizione culturale comune, dopo la guerra sociale i Romani cercavano assiduamente di introdurre sulla penisola italica un comune sentire italico affinché tutti gli abitanti si sentissero parte di una sola comunità, come se tutti avessero una tradizione comune e delle radici comuni, cosa che Augusto riuscì ad ottenere: "il latino era parlato dappertutto; non c'erano più Etruschi; non c'erano più Sanniti".

\footnotetext{
I6 Bratož, Rimska zgodovina.

17 Jorma Kaimio, "The ousting of Etruscan by Latin in Etruria" in Studies in the Romanization of Etruria, ed. Peter Brunn (Roma: Bardi Editore, 1975): $85-245$
} 


\section{I cambiamenti nell'autocoscienza etnica} delle popolazioni italiche prima e dopo la guera sociale

Parlare dell'appartenenza o dell'identità etnica vuol dire prendere in considerazione due punti di vista diversi: quella dei "vincitori", nel nostro caso i Romani, e il punto di vista delle popolazioni sottomesse, cioè quello degli altri abitanti italici. La maggior parte delle fonti ci descrive il punto di vista dei Romani, che risulta essere più chiaro, mentre invece più complesso è capire il senso di appartenenza etnica delle popolazioni italiche.

\section{Romani}

La percezione dei Romani è analizzabile attraverso le fonti degli storici latini e greci, la guerra civile fu infatti descritta dai storiografi greci, come Appiano (Bella civilia), Diodoro (rimasti solo alcuni frammenti) e Plutarco (Marius) e da quelli latini, come Tito Livio (su questo periodo ci sono rimaste solo le Perioche), Velleio Patercolo e più tardi anche Floro.

Per conoscere meglio il rapporto che i Romani avevano nei confronti degli Italici prima della guerra sociale è però necessario analizzare anche alcuni frammenti delle Origines di Catone, soprattutto dal secondo e terzo libro, nei quali lo scrittore latino si impegna a valorizzare le tradizioni degli italici. Catone infatti si prefigge lo scopo di sostenere quelle varianti della tradizione secondo le quali erano stati i Sabini il popolo originario della penisola italica, dai quali derivavano tutti gli altri popoli italici dell'Italia centrale. Rileva inoltre l'unità italica che si basa sui mores maiorum e sulle virtù come la fides, austeritas, virtus, quest'ultima concepita soprattutto come forza bellica.

Porro Lacedaemonios durissimos fuisse
omnis lectio docet, Sabinorum etiam m[ai]
ores populum Romanum secutum idem
Cato dicit: merito ergo $»$ severis $\ll$, qui et a
duris parentibus orti sunt et quorum dis- ciplinam victores Romani in multis secuti sunt. $^{\mathrm{I}}{ }^{8}$

Catone spiega che i Sabini erano duri, perché erano stati educati secondo severi principi educativi degli Spartani e continua con l'affermazione che proprio così come i Sabini, anche tutti i Romani devono essere coraggiosi e abili nella guerra come lo erano stati i loro antenati. I Sabini mantenevano la propria virtù integra e facevano attenzione a non essere troppo in contatto con altre popolazioni ${ }^{19}$. Come viene spiegato da Letta, lo scopo principale di Catone era di propagare l'origine italica delle città romane, perciò nella propria opera smentisce le sempre più diffuse leggende sull'origine greca delle città italiche e si avvicina invece di più alle origini italiche con lo scopo di avvalorare la forza delle popolazioni italiche come esempio di virtù per i Romani. Tutta l'opera di Catone è segnata da una forte ideologia italica che può essere percepita soprattutto nel secondo e terzo libro, nel quale Catone spiega l'origine e lo sviluppo delle singole tribù che avevano abitato o abitavano la penisola italica. Il rapporto di Catone verso gli Italici rimane comunque ambiguo; dal passo citato si può interpretare che Catone fosse stato convinto delle origini sabine dei Romani (a parentibus orti sunt). Purtroppo i rari frammenti non possono darci un quadro più dettagliato e chiaro del rapporto di Catone verso gli Italici. Potremmo dedurre che lo scrittore romano pensava ad un origine comune dei Romani o forse che i Romani fossero stati una mescolanza etnica tra gli Etruschi, i Sabini e i Latini, il che probabilmente era anche l'opinione più diffusa a Roma. Non possiamo però capire il rapporto di Catone verso gli altri popoli italici, che venivano invece considerati dei nemici dai Romani, come viene spiegato da Tito Livio nel suo racconto sulla guerra sociale. Lo storico romano appoggia la linea ufficiale

\footnotetext{
I 8 Fr. $93=\mathrm{ORF}_{3} \mathrm{I}_{2} 8$

19 Cesare Letta, "I legami tra i popoli italici nelle Origines di Catone: tra consapevolezza etnica e ideologia" in Patria gentibus diversis una? Unità politica e identità etniche nell' Italia antica, ed. G. Urso (Pisa, 2007): 171-195.
} 
della repubblica romana e descrive la guerra dal punto di vista dei vincitori.

\section{Complures populi ad hostes defecerunt. Cum P. Rutilius cos. parum prospere ad- versus Marsós pugnasset et in eo proelio cecidisset, C. Marius, legatus eius, meliore eventu cum hostibus acie conflixit. ${ }^{20}$}

Elencando i vari gruppi etnici, come per es. i Marsi che si sono aggregati ai nemici, Livio spiega che la guerra civile era una guerra contro un nemico esterno, poiché per gli Italici era usato il termine "hostes".

Tra le fonti del principato augusteo citiamo invece Strabone, che nel primo libro della sua storia ci trasmette la descrizione delle popolazioni italiche del suo tempo e un'interessante informazione:

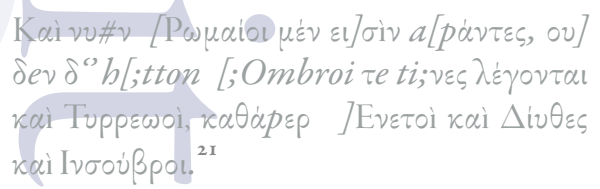

Le popolazioni italiche si chiamano tra di loro con i propri nomi, però nel contempo sentono l'appartenenza politica ad un stato soltanto e sono perciò cittadini dell'impero romano. Quindi ancora nel periodo del principato la loro identità resta ben definita, perché differiscono dal popolo romano mantenendo il loro nome il che è uno dei criteri principali per la definizione dell'identità di un gruppo etnico. Se quindi gli appartenenti alle singole popolazioni italiche si chiamavano tra di se ancora con il proprio nome, significa, che era ben radicato il loro senso di appartenenza al gruppo etnico e non invece al popolo romano. Strabone dimostra inoltre che ancora verso la fine del primo secolo a. C. le singole popolazioni mantenevano viva la propria autocoscienza e nonostante si siano inseriti nello stato romano, si identificavano ancora col proprio gruppo etnico.

La stessa problematica viene trattata anche da Cicerone nel De legibus, quando afferma che

\footnotetext{
20 Livy, Epit. 73.3-4. Livio usa lo stesso termine $\gg$ hostes $\ll$ anche in altri passi: Livy, Per., 73, 6; 75, 4, 6 .

2 I Strabo, I, io.
}

ogni cittadino romano ha due patrie: la prima è quella, dove ogni cittadine era nato, la seconda quella che lo ha adottato:

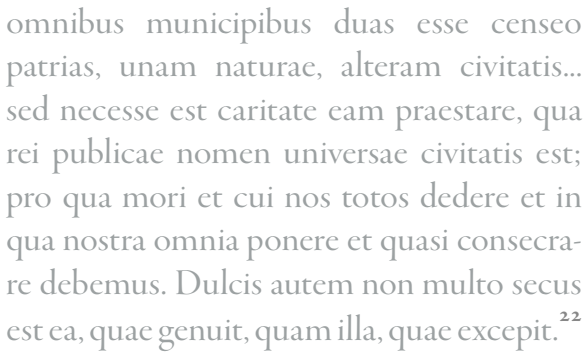

Entrambe le patrie sono certamente molto vicine al cuore di ognuno, ma il retore romano aggiunge che secondo lui bisognerebbe dare la precedenza a quella più ampia. Anche il senso di appartenenza al territorio rientra infatti tra i criteri per la definizione del gruppo etnico: $\mathrm{Ci}$ cerone nel proprio lavoro richiama l'attenzione al dilemma dei cittadini romani, abitanti delle province italiche che sentivano una lacerazione interna tra la propria patria e lo stato romano: sentivano infatti una forte connessione con le proprie radici, ma facevano già parte della nuova patria.

Anche per gli scrittori latini dell'età imperiale la guerra sociale e le popolazioni italiche rappresentano un interessante tema, descrivendolo però da un punto di vista diverso. Velleio Patercolo, storico dell'epoca augustea, elenca la causa della nascita della guerra sociale come una risposta lecita alla repressione di quella gente che difendeva lo stato con le proprie armi e che offrivano un numero doppio di soldati e cavalieri; lo storico romano giustifica il fatto avvenuto come la ribellione di una parte della popolazione che però faceva parte dello stesso popolo e addirittura della stessa gente:

quorum ut fortuna atrox, ita causa fuit ius tissima; petebant enim eam civitatem cuius imperium armis tuebantur; per omnes annos atque omnia bella duplici numero se militum equitumque fungi neque in eius civitatis ius recipi quae per eos in id ipsum pervenisset fastigatum ex quo eiusdem et 22 Cic. Leg. 2, 2, 5 
gentis et sanguinis ut externos alienosque fastidire posset. ${ }^{23}$

Patercolo usando il termine "sanguinis" fa capire che le popolazioni italiche erano secondo lui imparentate tra di loro, il che però non è una condizione essenziale dell'appartenenza allo stesso gruppo etnico. Lo storico vuole però sottolineare degli stretti legami genealogici tra il popolo romano e quelli italici con due termini, "gens" e "sanguis", che erano considerati come dei criteri essenziali per l'appartenenza ad un unico gruppo etnico. Una testimonianza molto simile viene fornita da Floro, scrittore del secondo secolo dopo C.:

\section{Quippe cum populus Romanus Etruscos, \\ Latinos, Sabinosque sibi miscuerit et unum ex omnibus sanguinem ducat, corpus fecit ex membris et ex omnibus unus est. ${ }^{24}$}

Floro con la metafora di un unico corpo con più membra rappresenta chiaramente il rapporto tra i Romani e gli Italici, e pone l'accento, che tutti erano originari da un unico sangue "unum ex omnibus sanguinem".

Un'altra fonte della guerra sociale è Appiano, che nel suo primo libro della storia romana spiega le cause della guerra sociale; prima di elencarle, racconta il lavoro politico di Gaio Gracco rilevando il suo impegno nell'inserire i Latini nell'amministrazione della repubblica:

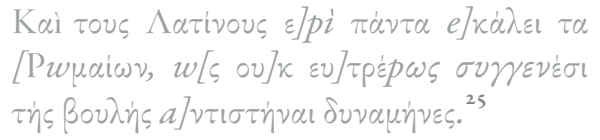

Anche Appiano mette in risalto i legami di sangue tra i Latini e i Romani usando il termine $\sigma \nu \gamma \varepsilon \nu \dot{\varepsilon} \sigma \mathrm{l}$, quindi la stessa origine genealogica, cioè appartenenti alla stessa stirpe. Quando invece parla delle popolazioni italiche, usa il termine

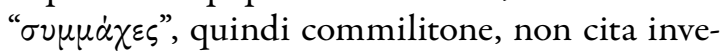
ce nessun legame parentale e nessun collegamento tribale tra di loro. Soltanto quando comincia a raccontare della guerra sociale, la chiama addi-

23 Vell. Pat., 2. 15. 2.

24 Flor., 2,6,1.

25 App.Sam. I, 99 . rittura "guerra civile" - $\varepsilon] \mu \phi \dot{\lambda} \lambda ı \nu$ pó $\lambda \varepsilon \mu o \nu$ (App. Sam. I, I78), una guerra fratricida quindi all'interno della stessa popolazione.

Analizzando quindi la descrizione della guerra sociale tra gli storici romani e greci nell'arco di un po' più di un secolo si può notare uno spostamento e una diversa visione dei fatti proprio riguardo al concetto d'identità etnica sia del popolo romano, ma soprattutto delle popolazioni italiche. Tito Livio considerava gli Italici come dei "nemici" e degli "stranieri". Velleio Patercolo che era un po' più giovane di Livio e più tardi anche Floro credono invece che le popolazioni italiche fossero appartenenti allo stesso gruppo etnico e alla stesso stirpe genealogica. Floro all'inizio parla ancora di Sabini, Latini e Romani, che dopo si sono congiunti in un unico corpo "unum ex omnibus sanguine". Velleio Patercolo invece con la definizione precisa "eiusdem et gentis et sanguinis" dimostra la percezione che tutti gli Italici erano appartenenti alla stessa popolazione e alla stessa stirpe. Dello stesso parere era anche lo storico greco Appiano che chiama la guerra sociale addirittura "guerra civile”, quindi una battaglia tra appartenenti allo stesso stato e alla stessa popolazione, il che indica che la percezione delle popolazioni italiche si è trasformata radicalmente nel giro di qualche decennio; il passo più grande è stato fatto nell'età augustea come si è potuto vedere dai pensieri di Cicerone e Livio che considerano gli Italici ancora come nemici.

\section{Il punto di vista delle popolazioni indigene}

Il rapporto dei Romani vincenti nei confronti degli Italici è quindi chiaro; molto più complesso è invece capire che cosa pensavano gli Italici di se stessi. La problematica dell'autocoscienza delle singole popolazioni è molto articolata, dato che si parla dıi un livello psicologico che è difficilmente percepibile a distanza di tanti secoli; ci rimane quindi soltanto l'analisi delle singole forme e criteri che definiscono l'appartenenza ad un gruppo etnico, cioè il modo in cui le singole popolazioni sentivano la propria identità. Lana- 
lisi è maggiormente ostacolata dalle scarse fonti che potrebbero fornirci qualche informazione in più sulla coscienza della propria identità. Ci manca soprattutto una tradizione letteraria originale che potrebbe direttamente offrire uno squarcio dei pensieri sulla vita e sull'identità di queste popolazioni. Ci rimangono comunque alcune testimonianze indirette dagli scrittori greci e latini, alcuni documenti epigrafici, soprattutto per il popolo degli Etruschi.

Tra i criteri di appartenenza ad un gruppo etnico rientra l'uso della lingua. Fino alla fine del $3^{\circ}$ secolo a. C. il latino è diventato la lingua di comunicazione anche nelle più piccole comunità e tribù della repubblica. In breve tempo svanì la lingua dei Volsci, nelle iscrizioni osche invece si possono notare molte interferenze con il latino. Con la graduale espansione dello stato romano anche la lingua latina ebbe la sua larga espansione, ma nonostante ciò non fu possibile estirpare così velocemente tutti gli idiomi locali. La buona conoscenza del latino è dimostrata anche dal fatto che molti autori latini, nati fuori Roma, conoscevano e usavano perfettamente il latino come lingua letteraria illustre. Nel secondo secolo a. C. il latino è diventato la lingua del commercio e di comunicazione tra diverse tribù italiche, ma "le parlate autoctone mostravano ancora la propria vitalità nonostante l'uso sempre più frequente del latino. (...) Qualcuno potrebbe supporre che le popolazioni e le tribù nel secondo secolo a. C. si rendevano conto della propria diversità che li distingueva dai Romani. Il loro innato e illimitato amore per l'autonomia era la causa principale delle loro reazioni ai fatti esteri., ${ }^{26}$ All'epoca della fioritura della repubblica romana esisteva quindi ancora una certa differenziazione tra il popolo romano e le restanti popolazioni italiche, il che lo dimostra l'uso assiduo della propria lingua e scrittura. Nel primo secolo a. C. il problema stava diventando sempre più sentito, i Romani insistevano sulla differenziazione per distinguersi dagli Italici sia culturalmente sia politicamente, mantenendo soprattutto i privilegi

26 Edward Togo Salmon, The Making of Roman Italy (London: Cornell University Press, 1985). che non erano concessi alle popolazioni italiche. Chiaro è che ai tempi della repubblica i Romani non avevano nessuna intenzione di assimilare gli Italici, anche la latinizzazione delle parlate locali della penisola era di minore interesse; soltanto a livello locale era permesso l'uso della lingua indigena nelle faccende che riguardavano il municipium stesso. Un esempio di questi cambiamenti è fornito da Livio, secondo il quale la città di Cuma raccolse una petizione richiedendo fosse usato il latino come lingua ufficiale del municipium; questo diritto gli è stato poi concesso da parte del senato romano. ${ }^{27}$ Quest'esempio ci dimostra che nelle pratiche comuni della città veniva usata la parlata locale e non il latino. Gli storici romani comunque non approfondiscono la questione della politica linguistica romana, il che ci dimostra che il problema neanche si poneva. Erano soltanto interessati al fatto che il latino diventasse la lingua di comunicazione e nel contempo non si prefiggevano lo scopo di estirpare le parlate locali. D'altra parte la conoscenza della lingua latina era utile agli abitanti della penisola italica perché potevano così ottenere privilegi, commerciare e mantenere i contatti con il mondo esterno. Kaimio del resto mette in risalto il fatto che i Romani non avevano nessun interesse ad allargare la propria lingua e cultura, perché così facendo avrebbero dato una ragione e una possibilità in più agli italici di aggregarsi contro di loro, mentre nel loro interesse era mantenere la dispersività delle tribù italiche. In sostanza fino alla guerra sociale i Romani volevano mantenersi ben lontani dalle popolazioni italiche e accentuavano la loro diversità sia culturale che linguistica e collegata a questa anche quella etnica.

Dopo la guerra sociale invece le cose cambiarono: gli abitanti della penisola italica divennero sul piano politico cittadini romani, e anche la diffusione del latino divenne più marcata; le lingue come quella etrusca, messapica, sabina cominciavano ad estinguersi. La latinizzazione della penisola italica è collegata anche alla conquista politica dei territori ed è ovviamente più

27 》Cumanis eo anno petentibus permissum, ut publice Latine loquerentur $\ll$ (Livy, Per. 40.42.13) 
forte e avanzata in quei territori che erano più vicini a Roma; un ruolo importante era svolto dalle infrastrutture, come le strade, le città, le colonie ecc. e proprio perciò è chiaro perché le città più vicine al mare si svilupparono presto in centri multiculturali, mentre invece quelle all'interno rimanevano nella mani delle popolazioni italiche. Kaimio del resto individua che alcune scritte in certe lingue italiche si sono mantenute a lungo anche dopo la conquista romana del territorio, e come esempio cita soprattutto le scritte messapiche al sud dell'Italia: la lingua messapica infatti rimase lingua di comunicazione fino alla fine della repubblica ${ }^{28}$.

Diversa era invece la situazione della lingua greca che si mantenne a lungo nella parte meridionale della penisola addirittura a tal punto che ancora oggi esistono comunità greche sulla penisola italica. Le cause di questa vitalità della lingua sono molto chiare: le colonie greche avevano mantenuto da sempre un rapporto molto stretto con le proprie metropoli che offrivano alle colonie un sostegno continuo e anche un supporto culturale assiduo. La lingua greca manteneva un alto livello di prestigio sociale in tutta l'area mediterranea dato che era diventata il modello culturale. Il privilegio sociale del greco non è quindi comparabile a quello delle altre lingue italiche.

Mentre quindi il latino si stava espandendo sempre di più, le lingue italiche erano in estinzione, fatto che può dimostrare anche un basso livello di autocoscienza etnica delle popolazioni italiche. La causa di un declino così veloce delle parlate locali può essere attribuito a diversi fattori, tra i quali vanno elencati soprattutto un basso livello di istruzione, la mancanza di un sistema scolastico che avrebbe potuto trasferire tradizioni, cultura, lingua e conoscenze e con questo anche un'identità etnica alle generazioni più giovani. Questi fattori erano al contrario molto ben presenti nelle colonie greche che mantenevano viva la propria lingua e le curavano ${ }^{29}$.

\footnotetext{
28 Oronzo Parlangeri, Studi messapici (Milano: Istituto Lonbardo di scienze e lettere, 1960).

29 Livy, Per., 24.3.1 i; Vell. Pat. I.4.2.
}

Le confederazioni politiche che nascevano tra le varie popolazioni erano soltanto alleanze con lo scopo principale di una ribellione anti-romana. Queste confederazioni si costituivano di solito in base a un denominatore comune che però era ogni volta diverso: a volte si aggregavano popolazioni sul principio delle loro credenze religiose, altre della volontà politica; queste confederazioni non nacquero però mai su un principio etnico, in base al quale le tribù avrebbero potuto aggregarsi, perciò non si formò neanche mai un'entità politica su base etnica. La mancanza di questo elemento comune ha portato anche al fatto che le fondamenta, sulle quali nacquero queste confederazioni, si sgretolarono presto, dato che le popolazioni non avevano una credenza comune, dei miti, leggende, cultura e religione comuni, il che avrebbe potuto aumentare il loro senso di appartenenza ad un gruppo. Ciò non significa che le tribù italiche erano assolutamente indifferenti alle proprie credenze cioè alla propria identità; molte popolazioni avevano la propria memoria storica e i propri miti sulle loro origini il che manteneva viva anche la loro identità. Ma questa identità era evidentemente troppo debole per potersi mantenere nel tempo.

\section{Il senso di appartenenza degli Etruschi e dei Sanniti}

Cercheremo adesso di definire l'identità etnica nel caso di due popolazioni italiche che risposero diversamente alle conquiste romane sulla penisola italica. Saranno presi in esame da una parte gli Etruschi che raggiungevano secondo le fonti antiche un alto grado di acculturazione, e i Sanniti, che rappresentano invece l'antitesi degli Etruschi sul piano culturale, mentre invece a livello militare erano molto efficaci e riuscirono a lungo a opporsi all'espansone romana. Il rapporto che i Romani avevano nei confronti di entrambe le popolazioni mostra una viva ambivalenza, poiché rispondevano diversamente alle sommosse degli uni e degli altri. L'esame delle due popolazioni prenderà in considerazione soprattutto la loro autocoscienza etnica. 
Luciana Aigner Foresti ha cercato, in base a diverse fonti storiche, epigrafiche e letterarie, di capire il grado di autocoscienza degli Etruschi analizzando i vari vincoli culturali, politici e religiosi che portarono gli Etruschi ad una omogeneità culturale e coscienza di se stessi come di una popolazione autonoma che si rendeva conto della propria specificità e si differenziava dagli altri $^{3 \circ}$. Sul piano politico ci sono stati diversi tentativi, dai quali si può evincere il desiderio degli Etruschi di raggruppamento all'interno del popolo stesso. Oltre alle varie iscrizioni e fonti storiche che mettono in risalto il fatto che gli Etruschi chiamavano tutti se stessi Rasna ${ }^{31}$, bisogna sottolineare l'aggregazione politica delle dodici città etrusche che spesso intervenne nel confronti dei Romani come un'unità politica autonoma e omogenea. Esistono tra gli storici ancora posizioni diverse riguardo a questa unità politica delle dodici città etrusche: molti non sono convinti che in realtà esistesse davvero, sottolineando che l'ordinamento politico degli Etruschi era simile a quello greco delle città-stato e che in realtà questa confederazione non fosse in realtà mai esistita.

Tra i fattori che determinano un gruppo etnico c'è anche la memoria storica che era per gli Etruschi veramente molto ben definita, dato che conosciamo la divisione della storia etrusca in dieci saecula ${ }^{32}$. Ci sono rimasti anche alcuni frammenti delle Tuscae Historiae nei testi dello scrittore romano Censorino che ci dimostrano una viva coscienza della propria memoria storica comune degli Etruschi e che del resto viene anche sottolineata negli affreschi delle tombe sul mito di Rasenna, sul re Mastarna o su fratelli Vipina. Anche gli scrittori romani sono convinti che gli Etruschi avessero cura dei propri alberi genealogici ${ }^{33}$. Quando gli Etruschi parlavano della propria storia, si parlava sempre di Rassena,

30 Lucia Aigner Foresti, "Gli Etruschi e la loro autocoscienza" in $A u$ tocoscienza e rappresentazione dei popoli nell' antichita, ur. Marta Sordi (Milano: Vita e pensiero, 1992), 93-113.

$31 \quad$ Dion. Al. I.30.3

32 Marta Sordi, "I saecula degli Etruschi e gli ostenta" Rivista storica italiana $\mathrm{II}_{4}$, no. 3 (2002), $715-725$.

33 Pers. 3.27; Orazio su Mecenate. probabilmente però consideravano se stessi come un popolo autoctono, come scrive Dionisio D'Alicarnasso, che "pur dedicando grande spazio al problema dell'origine degli Etruschi, non si sofferma a raccontarci esplicitamente cosa gli Etruschi stessi pensavano sulla loro origine, anche se è probabile che se fossero stati di parere diverso dal suo, ce lo avrebbe detto e lo avrebbe discusso $\ll{ }^{34}$ Secondo il parere di Dioniso quindi gli Etruschi sarebbero stati una popolazione autoctona con le proprie origini nell'eroe Rassena. Tra i fattori principali della coscienza degli Etruschi la Foresti elenca anche il fatto che più tardi Augusto aggregò tutte le città etrusche in un'unica regione, la VIIa regio, Strabone invece ci testimonia che la definizione terminologica per gli Etruschi Tuppìvol veniva usata ancora nel I ${ }^{\circ}$ secolo dopo C. ${ }^{35}$

Il fattore identificativo più importante per la dimostrazione di una forte coscienza etnica degli Etruschi è proprio la loro dimensione religiosa. Propria la religione è quel settore per il quale gli Etruschi erano anche molto conosciuti: i loro dei, le credenze, incontri al Fanum Voltumnae, dove i rappresentanti di varie città etrusche sacrificavano insieme agli dei o anche molto famosa era la loro aruspicina, cioè l'arte di predire il futuro interpretando i segni della natura. L'insieme di tutti questi fattori ci dimostra un forte senso di appartenenza alla comunità religiosa etrusca.

Attraverso queste testimonianze gli Etruschi svilupparono anche la loro memoria storica e consolidarono le proprie tradizioni culturali e politiche, il che ci indica che il loro senso d'identità etnica era la conseguenza di una scelta volontaria e quindi aprioristicamente era molto forte $\mathrm{e}$ ancorato. Questo viene confermato dal loro desiderio di mantenere vive le proprie tradizioni il che è uno dei fattori più importanti per l'identificazione etnica. I resti archeologici dimostrano nel contempo anche un forte sviluppo artistico che era impregnato sì anche di cultura greca, ma che manteneva alcune caratteristiche che gli

34 Foresti, "Gli Etruschi e la loro autocoscienza", 93-I I3.

35 Strabo, I, IO 
davano una patina identificativa particolare. Oltre a tutto ciò bisogna anche aggiungere che gli Etruschi avessero mantenuto la loro lingua e la loro scrittura ancora a lungo come lo testimoniano le iscrizioni.

Soltanto nel primo secolo dopo C. la scrittura e la lingua etrusca stavano cominciando ad estinguersi e prendevano posto la lingua e la scrittura latina. Come menzionato all'inizio la lingua non è l'unico criterio di identificazione di un gruppo etnico, è però anche vero che è un fattore importante e in molti casi è proprio la lingua quella che accomuna gli appartenenti ad un unico gruppo etnico e mantiene la loro identità. Se gli Etruschi sono quindi considerati anche una comunità linguistica, nel loro caso fu proprio la lingua, il primo fattore che venne trascurato. La storica Marta Sordi ha a lungo studiato la storia etrusca arrivando alle conclusioni che gli Etruschi si rendevano conto della propria fine e questo sia dal punto di vista politico che anche culturale ed etnico, poiché si stavano per terminare i famosi dieci saecula che erano previsti per la loro storia; perciò hanno cominciato di proprio conto a tradurre i propri testi in latino con lo scopo di mantenere vivo il ricordo degli Etruschi, le loro tradizioni, la loro religione soprattutto all' interno dello stato romano ${ }^{36}$. Brunn ci fa sapere invece che se gli Etruschi tralasciarono la propria lingua relativamente presto, mantennero invece a lungo le proprie tradizioni sepolcrali e non si assimilarono alle tradizioni romane ${ }^{37}$. Tra tutte le popolazioni italiche furono infatti proprio gli Etruschi quelli che si distinguevano di più dai Romani, erano culturalmente coscienti, avevano la propria lingua e scrittura, la propria religione e le proprie tradizioni, erano però i pri$\mathrm{mi}$ ad accorgersi che avrebbero dovuto abbandonare la propria lingua e il proprio nome. La Sordi aggiunge che erano anche gli unici che però dall'altra parte mantennero anche all'epoca del tardo impero i propri culti religiosi e influirono parecchio sulla concezione religiosa dei Romani.

36 Marta Sordi, "Il paradosso etrusco: il "diverso" nelle radici profonde di Roma e dell' Italia romana" in Patria gentibus diversis una? Unità politica e identita etniche nell' Italia antica, ed. G. Urso (Pisa, 2007), 89-97.

37 Brunn, Studies in the Romanization of Etruria.
Nella cultura romana hanno portato la propria arte dell'aruspicina che i Romani mantenevano viva ancora per molti secoli dopo che il nome degli Etruschi era già scomparso.

Le conclusioni quindi ci portano a credere che gli aristocratici Etruschi avessero una forte coscienza di se stessi e della propria appartenenza ad una comunità etnica autonoma che aveva anche delle connotazioni politiche, artistiche, culturali e religiose. Un tale sviluppo ha permesso che la classe d'elite avesse sviluppato un senso di superiorità sulle altre popolazioni italiche e poteva perciò anche controllarli. Questo lo testimonia anche Catone, quando dice che probabilmente tutta l'Italia era sottomessa agli Etruschi. ${ }^{38}$ Nonostante un'autocoscienza così sviluppata però non potevano fermare il processo di romanizzazione che avrebbe comunque portato gli Etruschi ad abbandonare la propria lingua e anche il proprio nome, anche se, grazie alla loro lungimiranza ebbero la possibilità di arricchire con le proprie tradizioni e sapere la cultura romana.

Per una diversa strategia di opposizione allo stato romano invece optò la popolazione sannitica che viene descritta da Livio:

\section{Bello non abstinebant: adeo ne infeliciter quidem defensae libertatis taedebat et vinci quam non temptare victoriam malebant. ${ }^{39}$}

Dalla storia di Livio e da altre fonti possiamo capire che i Sanniti erano uno dei popoli più belligeranti, contro i quali i Romani avevano combattuto. Per loro la libertà politica era il valore più alto, per la quale volevano combattere fino all'ultimo. Da questo potremmo dedurne che anche la loro autocoscienza era alta. I Sanniti erano anche i primi a chiamare la penisola italica "Italia" per aggregare tutte le popolazioni italiche nella guerra contro Roma.

Sui Sanniti non ci sono molte fonti, i resti della loro cultura sono scarsi, sia sul piano archeologico che su quello storico non disponiamo di molte informazioni, perciò capire il loro livello

»quia in Tuscorum iure paene omnis Italia fuerat « (Cato, Orig. 2.67)

Livy Epit. 10. 31.14 
di autocoscienza è più difficile. Intanto si pone già subito all'inizio la domanda se i Sanniti si consideravano come una popolazione unitaria o erano soltanto un insieme di varie tribù in parte sviluppate culturalmente. Riguardo al loro livello di autocoscienza cercheremo di analizzarlo sulla base della loro organizzazione politica, culturale e religiosa.

I Sanniti non conoscevano l'organizzazione politica in municipia come i Romani e non conoscevano neanche le città-stato dei Greci e degli Etruschi. La loro unità politica erano i touto, cioè comunità di abitanti, ai quali presiedevano $i$ sacrati - sacerdoti. Non possiamo quindi parlare di un'unica unità politica, ma al massimo di una confederazione di touti. I tentativi di organizzazione delle tribù sannitiche si basavano sulla forma "pagano-vicana", dato che l'unità principale era il pagus, cioè il villaggio come il centro abitativo dei Sanniti, l'organizzazione urbana invece non era presente dai Sanniti. Questa popolazione venne in contatto con la politica espansionistica di Roma nel quarto e terzo secolo a. C., ma i Sanniti si opponevano molto efficacemente ai Romani, aggregandosi agli Oschi e fondando la lega sannitica. Si trattava di una forte lega militare e politica che aveva anche un fattore religioso, ma lo scopo principale rimaneva comunque la politica antiromana. I Romani non riuscirono a trovare appoggio in questo caso nei ceti aristocratici dei Sanniti, come per esempio sono riusciti a farlo con i Campani, gli Apuli e i Liguri, perciò si è arrivati alle guerre sannitiche. Più tardi la lega sannitica si congiunse anche con il re Pirro, mentre durante l'assedio di Annibale alla fine del terzo secolo non si trovano più tracce della lega.

Riguardo all'aspetto religioso le tribù sannitiche non avevano una dimensione religiosa comune. Le divinità principali erano quelle uguali alle altre popolazioni italiche, tra le quali si cita soprattutto il Ver sacrum, durante il quale si sacrificava bestie e oggetti alle divinità. Questo rito rappresentava un rito comune a tutte le comunità italiche, ma soltanto i Sanniti lo prefiggevano regolarmente sul proprio territorio. Per i
Sanniti era infatti tipica la polilatria, cioè la venerazioni di più divinità sullo stesso luogo. L'iscrizione di Anona nella lingua osca testimonia che in quel luogo erano venerati 17 divinità.

La lingua dei Sanniti, chiamata lingua osca dalle popolazioni che abitavano questi territori prima, mostra un alto livello di sviluppo: le iscrizioni infatti mostrano che si basava su rigide e ben definite regole grammaticali. Era diffuso in tutta la penisola italica ed era usato da tutte le popolazioni della Sicilia settentrionale, dai Lucani e Mamertini fino agli Umbri. Le regole grammaticali sono molto simili a quelle latine, solo a livello fonologico, morfologico e ortografico sono evidenti delle chiare differenze. I Sanniti avevano anche una tradizione letteraria come viene testimoniato da Livio, purtroppo però nulla è rimasto. In sostanza, dai dati che ci sono noti, non possiamo parlare di un alto grado di autocoscienza tra i Sanniti, almeno non così come dagli Etruschi. Avevano sì una vita politica organizzata, rappresentata da una forma di confederazione politica di diverse tribù; sul piano religioso non ci è possibile ricostruire qualche elemento identificativo che li distinguerebbe dalle altre popolazioni italiche. Avevano sì la propria lingua e la propria tradizione letteraria, ma ne uno ne l'altro non può essere un fattore definitivo per avvalorare una sviluppata coscienza etnica. Rimane comunque da capire perché erano stati proprio i Sanniti a opporsi il più a lungo ai Romani, come lo si può capire dalle fonti storiche. A differenza degli Etruschi che si sono sottomessi alla pressione politica romana e l'hanno accettato cercando di inserirsi il più produttivamente possibile nel processo politico romano, i Sanniti dall'altra parte invece si sono opposti assiduamente a ciò. Le guerre sannitiche che si svolgevano ancora nel quarto e terzo secolo a. C. sono la prova di un aspro conflitto tra due antagonisti equivalenti, che si consideravano l'un l'altro dei "hostes". Questo fattore storico convalida la supposizione che un gruppo etnico comincia a prendere coscienza di se o fortifica la propria autocoscienza quando arriva un nemico esterno. Questo è successo probabilmente per i Sanniti che fino all'ar- 
rivo dei Romani erano stati soltanto una confederazione di villaggi, non una popolazione che aveva coscienza di se. Quando invece arrivò un nemico comune, si fondò la lega sannitica, basata non su interessi politici, religiosi e culturali, ma su quelli anti-romani. I Sanniti quindi probabilmente avevano un basso livello di autocoscienza, e non si sentivano appartenenti alla stessa comunità etnica.

\section{Conclusione}

Dall'analisi di questi due casi si può capire che il $\stackrel{m}{m} \quad$ livello di autocoscienza dei singoli popoli italici era molto diverso e divergente: mentre gli Etruschi avevano un alto livello di autocoscienza e un livello sviluppato di appartenenza al proprio gruppo etnico, i Sanniti non avevano una situazione così sviluppata. Allo stesso modo anche la tradizione culturale delle popolazioni italiche non poteva opporsi alla romanizzazione culturale e anche una debole coscienza etnica non poteva mantenere la loro autonomia. Prendendo in considerazione tutti questi fattori il senato romano riuscì relativamente presto a risolvere il problema dei socii: subito quando fu offerta agli Italici la cittadinanza romana, tutti gli sforzi di fondare uno stato italico svanirono. Da allora in poi l'atteggiamento dei Romani nei confronti degli Italici cambiò, non erano più visti come "externi" o "nemici", ma si cercavano invece le radici comuni e gli Italici diventarono addirittura consanguinei. A causa di una debole autocoscienza degli italici il processo di romanizzazione a livello culturale fu abbastanza veloce, poiché nel giro di qualche decennio le popolazioni italiche abbandonarono il proprio nome, la propria lingua e scrittura. Cambiò appunto anche l'atteggiamento dei Romani nei confronti degli italici, fatto dovuto però anche alla forte propaganda augustea per formare un'unità culturale e politica unitaria, cioè l'Italia.

\section{Povzetek}

V obdobju med zavezniško vojno (9I - 88 pr. Kr.) je prišlo do pomembnih sprememb pri vprašanju etnične pripadnosti italskih ljudstev. Avgustov politični program je stremel za poenotenjem celotnega italskega polotoka $\mathrm{v}$ eno samo politično, kulturno in etnično enoto, kar pa še v času zavezniške vojne ni bilo tako samoumevno. Primera Etruščanov in Samnitov jasno prikazujeta razlikev nivoju samopodobe in etnične zavesti različnih ljudstev v Italiji: medtem ko so imeli prvi visoko razvito kulturo in posledično tudi zavest o lastni etnični pripadnosti, Samniti in številna druga ljudstva tega niso imela, zato pa so se lažje vključevala v rimsko državo. V trenutku, ko je Rim predlagal državljanstvo vsem italskim ljudstvom, se je tudi odnos do teh ljudstev spremenil: niso bili več »externi $\ll$ ali $\gg$ nasprotniki $\ll$, temveč so v zgodovinskih in mitografskih zgodbah iskali skupne bratske korenine. Italska ljudstva so se sicer odrekla svojemu imenu, navadam, kulturi in tradicijam, nekatera od teh (predvsem Etruščani) pa so rimski kulturi zapustila svoje navade. Cesarju Avgustu je tako s svojim političnim programom uspelo ustvariti kulturno enoto po geslu: »Iuravit in mea verba tota Italia sponte sua ${ }^{40}$

\section{Summary}

In the period between the Allied War (9I-88 BC) there were important changes in the ethnic question of Italian peoples. The Augustan political program sought to unify the entire Italian peninsula into a single political, cultural and ethnic unit, which, however, was not a self-evident before and during the Allied War. The examples of Etruscans and Samnites clearly show the differences in the level of self-image and ethnic awareness of different peoples in Italy: while the first had highly developed culture and, consequently, the awareness of their own ethnic affiliation, the Samnites and many other peoples did not have it and therefore, were easily subjected to the Roman state. At the moment when Rome proposed citizenship to all the Italians, the attitudes to there peoples was also changed: they were no longer "externa" or "opponents", but in the historical and mythographic stories they sought common fraternal roots. The Italian people have renounced their name, habits, culture and traditions, while some of them (especially Etruscans) have abandoned their habits to Roman culture.Thus, with his political program, Emperor Augustus managed to create a cultural unit after the motto from his Res gestae: "Iuravit in mea verba tota Italia sponte sua".

$40 \quad$ Aug. Res gestae, 25 . 


\section{Bibliografia}

Aigner Foresti, Lucia. "Gli Etruschi e la loro autocoscienza” in Autocoscienza e rappresentazione dei popoli nell'antichità, ed. Marta Sordi, 93-I13. Milano: Vita e pensiero, 1992.

Aigner-Foresti, Lucia. "Quod discinctus eras, animo quoque, carpitur unum « (Maec., El. I.2I)", Contributi dell'Istituto di Storia Antica 17 (1991): 20I-214.

Bandelli, Gino. "La politica romana nell'Adriatico orientale in età repubblicana", in Seminario storicoarcheologico su "L'arco adriatico in etḋ romana e altomedievale”, I68-2I4. Trieste, 1986.

Bratož, Rajko. Rimska zgodovina. Ljubljana: Študentska založba, 2007.

Cacciari, Massimo. "Digressioni su impero e tre Rome". Micromega 5 (200I): 43-63.

Clemente, Guido. Guida alla storia romana. Milano: Mondadori, 200I.

Farney, Gary D. Ethnic identity and aristocratic Competition in Republican Rome.

Cambridge: Cambridge University Press, 2007.

Gruen, Erich. Culture and National Identity in Republican Roma. New York: Ithaca, 1984.

Hall, Jonatan M. Ethnic Identity in Greek Antiquity. Cambridge: Cambridge Core, 1997.

Kaimio, Jorma. "The ousting of Etruscan by Latin in Etruria" in Studies in the Romanization of Etruria, ed. Peter Brunn, 85-2 45. Roma: Bardi Editore, 1975.

Letta, Cesare. "I legami tra i popoli italici nelle Origines di Catone: tra consapevolezza etnica e ideologia" in Patria diversis gentibus una? Unità politica e identità etniche nell'Italia antica, ed. G. Urso I7 I195. Pisa, 2007.

Lomas, Kathryn. Roman Italy: 338 BC - AD 200. London: Ruotledge, 1996.

Noel, Donald L. "A Theory of the Origin of Ethnic Stratification”. Social problems 16, no. 2 (I968): 28-34.
Parlangeri, Oronzo. Studi messapici. Milano: Istituto Lombardo di scienze e lettere, I960.

Salmon, Edward Togo. The Making of Roman Italy. London: Cornell University Press, 1985.

Sherwin White, Adrian Nicholas. The Roman Citizenship. Oxford: Oxford University Press, 1939.

Smith, Anthony D. The Ethnic Origins of Nations. Oxford: Blackwell Publishers, 1986.

Sordi, Marta. "I saecula degli Etruschi e gli ostenta”. Rivista storica italiana II 4, no. 3 (2002), 715-725.

Sordi, Marta. "Il paradosso etrusco: il "diverso" nelle radici profonde di Roma e dell'Italia romana" in Patria diversis gentibus una? Unità politica e identità etniche nell'Italia antica, ed. G. Urso, 89-97. Pisa, 2007.

Syed, Yasmin. Vergil's Aeneid and the Roman Self. Ann Arbor: The University of Michigan Press, 2005.

Toll, Kathrin. "Making Roman-ness and the Aeneid”. Classical Antiquity 16 (1997): 3456. 


\section{NAVODILA ZA AVTORJE}

Revija objavlja primarno v slovenskem jeziku, toda tudi v večjih svetovnih jezikih (angleščina, nemščina, francoščina, italijanščina, ruščina). V objavo se sprejmejo tudi članki v cirilici. V primeru tujejezičnega članka morata biti izvleček in povzetek poleg angleščine obvezno v slovenskem jeziku. Za oboje poskrbi avtor.

Članek (praviloma v obsegu 7000 , vendar največ 10.000 besed) naj ima na začetku: 1) naslov ter ime in priimek avtorja/-ice; 2) izvleček v slovenskem in abstract angleškem jeziku, do 250 besed; 3 ) ključne besede v slovenščini in angleščini (do 5); 4) kratko predstavitev avtorja/-ice (do roo besed v slovenščini in angleščini), navedena naj bo tudi organizacija zaposlitve. Članek naj po razpravnem besedilu vsebuje še: I) povzetek v slovenščini in angleščini ter 2) seznam virov in literature.

Prispevki naj bodo napisani v knjižni slovenščini (ali v knjižni različ̌ici katerega tujih jezikov, v kolikor gre za tujejezično delo) ob upoštevanju veljavnega pravopisa, v nasprotnem primeru si uredništvo pridržuje pravico, da članka ne recenzira oziroma ga zavrne.

Če je prispevek že bil objavljen v kaki drugi reviji ali če čaka na objavo, je treba to izrecno navesti.

Prispevek naj ima dvojni medvrstični razmik, tip črk naj bo Times New Roman, velikost 12 pik (v opombah 10). Besedilo naj bo levo poravnano, strani pa zaporedno oštevilčene. Odstavki naj bodo ločeni s prazno vistico.

Uporabiti je mogoče do tri hierarhične nivoje podnaslovov, ki naj bodo ośtevilčeni (uporabljajte izključno navaden $s l o g$, v prelomu bodo ravni ločene tipografsko): I. - I.I - I.I.I

Za poudarke uporabite izključno ležeći tisk(v primeru jezikoslovnih besedil, kjer so primeri pravilomavležečem tisku, lahkoza poudarke izjemoma uporabite polkrepki tisk). Ležeče pišite tudi besede v tujih jezikih. Raba drugih tipografskih rezov (podčrtano, velike male črke, krepko kurzivno ...) ni dovoljena. Ne uporabljajte dvojnih presledkov, prav tako ne uporabljajte preslednice za poravnavo besedila. Edina oblika odstavka, ki je dovoljena, je odstavek z levo poravnavo brez rabe tabulatorjev prve ali katerekoli druge vrstice v ostavku (ne uporabljajte sredinske, obojestranske ali desne poravnave odstavkov). Oglate oklepaje uporabljajte izključno za fonetične zapise oz. zapise izgovarjave. Tri pike so stične le, če označujejo prekinjeno bese... Pri nedokončani misli so tri pike nestične in nedeljive ... Prosimo, da izključite funkcijo deljenja besed.

Sprotne opombe naj bodo samooštevilčene (številke so levostično za besedo ali ločilom - če besedi, na katero se opomba nanaša, sledi ločilo) in uvrščene na tekočo stran besedila.

Citati v besedilu naj bodo označeni z dvojnimi (» «), citati znotraj citatov pa z enojnimi (") narekovaji. Izpuste iz citatov in prilagoditve označite s tropičjem znotraj poševnic /.../. Daljše citate (več kot s vrstic) izločite v samostojne odstavke, ki jih od ostalega besedila ločite $\mathrm{z}$ izpustom vrstice in umikom $\mathrm{v}$ desno. Vir citata označite $\mathrm{v}$ okroglem oklepaju na koncu citata. Če je avtor/-ica naveden/-a v sobesedilu, priimek lahko izpustite.
V besedilu označite najprimernejša mesta za likouno opremo (tabele, slike, skice, grafikone itd.) po zgledu: [Tabela I približno tukaj]. Posamezne enote opreme priložite vsako v posebni datoteki (v.eps, ai, .tif ali .jpg formatu, minimalna resolucija $300 \mathrm{dpi}$, tabele prilagajte v posebni datotetki v formatu .doc, grafe pa v formatu .xls, kjer naj ob grafu stoji tabela, ki je podlaga za graf). Naslov tabele je nad tabelo, naslov grafa/slike pa pod grafom/sliko.

Prostor, ki ga oprema v prispevku zasede, se šteje v obseg besedila, bodisi kot 250 besed (pol strani) ali 500 besed (cela stran).

Ob oddaji preda avtor uredništvu članek v formatu .doc in hkrati tudi.pdf.

Za citiranje literature in za pripravo seznama uporabljene literature se uporablja izkljucno stil Chicago, in sicer v obliki, kot je aktualna, tj. v svoji i6. izdaji (http://www.chicagomanualofstyle.org/home.html, 16. izdaja na razpolago na zahtevo tudi pri uredniku izdaje)

I: Enoavtorska monografija

a) Polna oblika reference pod crrto: Michael Pollan, The Omnivore's Dilemma: A Natural History of Four Meals (New York: Penguin, 2006), 99-100.

b) Kratka oblika reference pod črto: Pollan, Omnivore’s Dilemma, 3 .

c) Navedba v virih in literaturi: Pollan, Michael. The Omnivore's

Dilemma: A Natural History of Four Meals. New York: Penguin, 2006. II: Većavtorska monografija

a) Polna oblika reference pod črto: Geoffrey C. Ward and Ken Burns, The War: An Intimate History, 1941-1945 (New York: Knopf, 2007), 52

b) Navedba v virih in literaturi: Ward, Geoffrey C., and Ken Burns. The War: An Intimate History, 1941-1945. New York: Knopf, 2007.

III: Knjiga z urednikom

a) Polna oblika reference pod črto: Joel Greenberg, ed., Of Prairie, Woods, and Water: Two Centuries of Chicago Nature Writing (Chicago: University of Chicago Press, 2008), 42.

b) Kratka oblika reference pod črto: Greenberg, Prairie, Woods, and Water, 326-27.

c) Navedba v virih in literature: Greenberg, Joel, ed. Of Prairie, Woods, and Water: Two Centuries of Chicago Nature Writing. Chicago: University of Chicago Press, 2008.

IV: Poglavje v knjigi

a) Polna oblika reference pod črto: Glenn Gould, "Streisand as Schwarzkopf," in The Glenn Gould Reader, ur. Tim Page (New York: Vintage, 1984),310.

b) Kratka oblika reference pod črto: Gould, "Streisand as Schwarzkopf," 309 .

c) Navedba v virih in literaturi: Gould, Glenn. "Streisand as Schwarzkopf." In The Glenn Gould Reader, ur. Tim Page, 308-11. New York: Vintage, 1984 .

Gould, "Streisand as Schwarzkopf," 309 
V: Clanek v reviji

a) Polna oblika reference pod črto: Walter Blair, "Americanized Comic Braggarts," Critical Inquiry 4, no. 2 (1977):331-32.

b) Kratka oblika reference pod črto: Blair, "Americanized Comic Braggarts," 335 .

c) Navedba v virih in literaturi: Blair, Walter. "Americanized Comic Braggarts." Critical Inquiry 4, no. 2 (1977): 331-49.

VI: Clanek v reviji (digitalna objava; DOI)

a) Polna oblika reference pod črto: William J. Novak, "The Myth of the 'Weak' American State," American Historical Review Ir3 (June 2008): 758, doi:10.1086/ahr.113.3.752.

b) Kratka oblika reference pod črto: Novak, "Myth," 770 .

c) Navedba v virih in literaturi: Novak, William J. "The Myth of the 'Weak' American State." American Historical Review 113 (June 2008): 752--72. doi:10.1086/ahr.113.3.752., "Streisand as Schwarzkopf," 309.

VII: Članek v reviji (digitalna objava, URL)

a) Polna oblika reference pod črto: Wilfried Karmaus and John F. Riebow, "Storage of Serum in Plastic and Glass Containers May Alter the Serum Concentration of Polychlorinated Biphenyls," Environmental Health Perspectives II2 (May 2004): 645, http://www. jstor.org/stable/3435987 (datum dostopa do spletne strani).

b) Navedba v virih in literaturi: Karmaus, Wilfried, and John F. Riebow. "Storage of Serum in Plastic and Glass Containers May Alter the Serum Concentration of Polychlorinated Biphenyls." Environmental Health Perspectives II2 (May 2004): 643--47. http:// www.jstor.org/stable/3435987.

O morebitnih drugih posebnostih se posvetujte z uredništvom

Naslov uredništva: dr. Gregor Pobežin, Fakulteta za humanistične študije Univerze na Primorskem, Titov trg 5,

SI-6000 Koper, gregor.pobezin@fhs.upr.si 

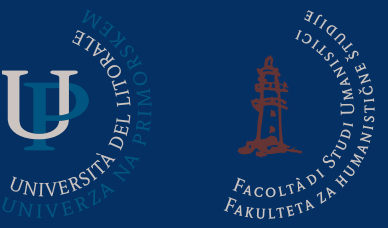

Založba Univerze na Primorskem www.hippocampus.si ISSN 2350-5443

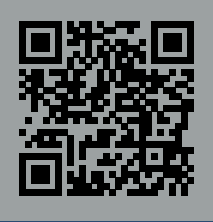

